American Journal of Art and Design
2020; 5(3): $63-70$
http://www.sciencepublishinggroup.com/j/ajad
doi: $10.11648 /$ j.ajad.20200503.12
ISSN: $2578-7799$ (Print); ISSN: $2578-7802$ (Online)

\title{
Metal Fasteners for the Local Fashion Accessories Industry in Ghana
}

\author{
Cyril Etornam Adala, Isaac Kwabena Agyei*, Samuel Baah Kissi \\ Department of Industrial Art, Kwame Nkrumah University of Science and Technology, Kumasi, Ghana \\ Email address: \\ etorcyl@yahoo.co.uk (C. E. Adala), ikegyei@gmail.com (I. K. Agyei), Kissisamuelbaah@yahoo.com (S. B. Kissi) \\ ${ }^{*}$ Corresponding author
}

To cite this article:

Cyril Etornam Adala, Isaac Kwabena Agyei, Samuel Baah Kissi, Metal Fasteners for the Local Fashion Accessories Industry in Ghana. American Journal of Art and Design. Vol. 5, No. 3, 2020, pp. 63-70. doi: 10.11648/j.ajad.20200503.12

Received: July 17, 2020; Accepted: August 20, 2020; Published: August 27, 2020

\begin{abstract}
The fashion industry in Ghana has evolved over time and has created a large market for both the producers and retailers. Ghanaian fashion designers like Mawuli Okudzeto, Genesis Clothing and Kofi Ansah to mention but a few have been able to capture pure African values in their designs. Companies like Akosombo Textiles and TexStyles Ghana Ltd, Vlisco and Woodin are daily producing materials that are becoming so useful to local fashion designers and they in turn are producing the styles that we also enjoy wearing. Ghanaian designers are also making fashion accessories like bags, shoes, jewellery; belts, among others, to match the clothes that they produce. Although Ghanaian fashion designers use metal fasteners in designing clothes and accessories, unfortunately, most of these fasteners are imported products that do not have any philosophical relation with the Ghanaian people. Even worse, the jewellery industry does not consider this venture as a niche market and also as a platform to support local fashion designers to create a holistic Ghanaian concept in what we wear. This paper explored the possibility of producing metal fasteners for Ghanaian fashion accessories industry using the Practice-based research method. The inspiration for the project was the popular Ghanaian Akinkra symbols. The result of the study revealed that metal fasteners could be produced in the studio with local concepts giving a totality of Ghanaian fashion concepts. The study recommends that techniques for the production could also be improved by adopting new production practices such as laser cutting and investment casting methods.
\end{abstract}

Keywords: Fasteners, Metal Fasteners, Fashion Accessories, Lost Wax Casting, Piercing

\section{Introduction}

Fashion designers combine colours, shapes and concepts from all around them to create fabrics, clothing style and the accessories that we love to wear [1]. Metal fasteners on these accessories especially make them look trendier and more attractive. According to Turini, Fashion is about storytelling through clothing. It is a cultural influence, backstory or intellectual touchpoint that you can trace back to what you are wearing. We use it to escape the mundane, to embrace and celebrate tradition. It is about a sense of history and pride and it embodies a greater sense of purpose than just a garment tossed on to cover bodies making it the cultural construction of an embodied identity [2,3]. Fasteners according to Watkins are the essential part of a fastening system used to hold together at least two pieces of material. It is typically a single item (button) that often works in concert with another device (buttonhole) [4].
Although Friedel explains that the evolution of the zipper can be traced back to early human development where at some point in the ancient past; humans began to fasten their garments with devices [5], Epstein, Diana, and Safro, assert that the first written record of buttons is from the twelfth century [6]. A metal fastener would simply refer to the material used in making the fastener (in this case metal). According to Decorative Zips, fasteners go beyond just the functional purpose by playing a significant part in dictating a garment's style and aesthetics [7]. Ghanaian fashion designers like Mawuli Okudzeto, Genesis and Kofi Ansah to mention but a few have been able to capture pure African values in their designs. Companies like Akosombo Textiles and TexStyles Ghana Ltd, Vlisco and Woodin are daily producing materials that are becoming so useful to local fashion designers and they in turn are producing the styles that we also enjoy wearing. Ghanaian designers also make fashion accessories like bags, shoes, jewellery; belts, among others, to match the clothes that they produce. The peak of this was the 
declaration by Former President J. A. Kufour when he introduced the Friday wear for all public officers and private sectors to wear locally designed garments produced from locally manufactured fabrics as an initiative aimed at projecting a unique Ghanaian identity through the extensive use of local fabrics and designs. [8]

Willis and Boddy-Evans, asserts that Adinkra is a name of a group of cultural symbols for the people of Asante in Ghana and was believed to have had its origin form Gyaman, a former kingdom in present day Cote d'Ivoire [9, 10]. According to Bulgin, adinkra also means 'goodbye' or 'farewell' in Twi, the local dialect of the Asantes. It has therefore been the tradition of the Akans especially the Asantes, to wear cloth decorated with Adinkra symbols on important occasions like funerals to bid farewell to the deceased. Today, the Adinkra cloth is not only worn by the Asantes, but by other ethnic groups in Ghana on important social gatherings and festive occasions [11]. Bello opines that with the advent of tourism, the use of the symbols has evolved as they are now being used in creative design, advertising and jewellery [12]. Showing the widespread influence and diversified use of the symbols in modern times.

Even though Ghanaian fashion designers use metal fasteners in designing clothes and accessories, unfortunately, most of these fasteners the designers use, are imported products that have little or no relation with the philosophy of the Ghanaian people, although the design of the cloths looks appealing and acceptable yet the lack of relation of the fasteners and some fashion accessories makes them loose the entire representation of what we can call Ghanaian/African wear. Even worse, the jewellery industry does not consider this venture as a niche market and also as a platform to support our local fashion designers to create a holistic Ghanaian concept in what we wear. This paper therefore sort to explore the possibility of producing metal fasteners for the Ghanaian local fashion accessories industry.

\section{Materials and Methods}

The methodology used for the research was Practice-based research. Practice-based research according to Skains is experimenting with art in order to push boundaries, which involves the use of tools and equipment to explore various forming techniques employed in producing the work piece [13]. It was also used to document the systematic production processes of the metal fasteners. It also covered the various tools and materials used during the fabrication processes.

\subsection{Materials and Techniques}

Brass sheet was selected as the metal to be used for this project. Even though copper sheets, aluminium or stainless steel could be used, brass was chosen because it gives a nice golden looking colour and possess a good strength for the purpose. It is also a good material for lost wax casting which was adopted for some of the processes. Another observation made among local craftsmen and goldsmiths showed that piercing and traditional lost wax casting were the most basic techniques used by jewellers and the traditional casting artisans. Based on this finding, the researchers decided to employ these techniques so that anyone who would like to replicate or remake these items would find it easy to achieve.

\subsection{The Design Process}

The inspiration for the project was the popular Ghanaian Adinkra symbols. Upon realizing the need to demonstrate that metal fasteners can be made using local cultural symbols, the researchers developed sketches using selected Adinkra traditional concepts suitable for the execution of the work. The following are sketches that were made as shown in Figure 1 to Figure 6.

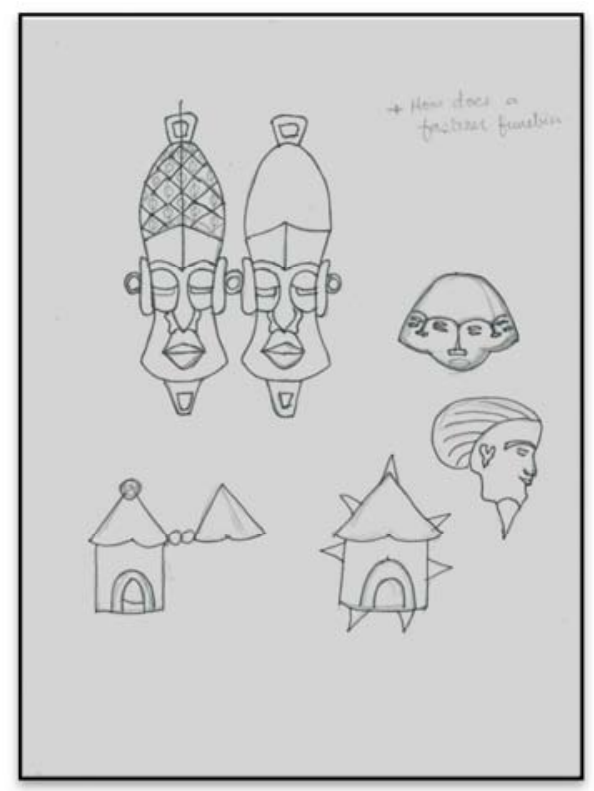

Figure 1. Sketches of ideas (I).

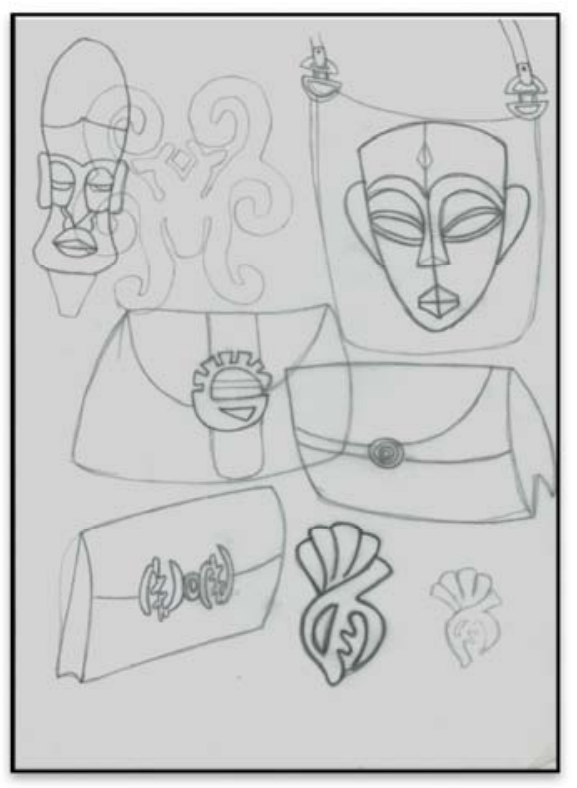

Figure 2. Sketches of ideas (II). 


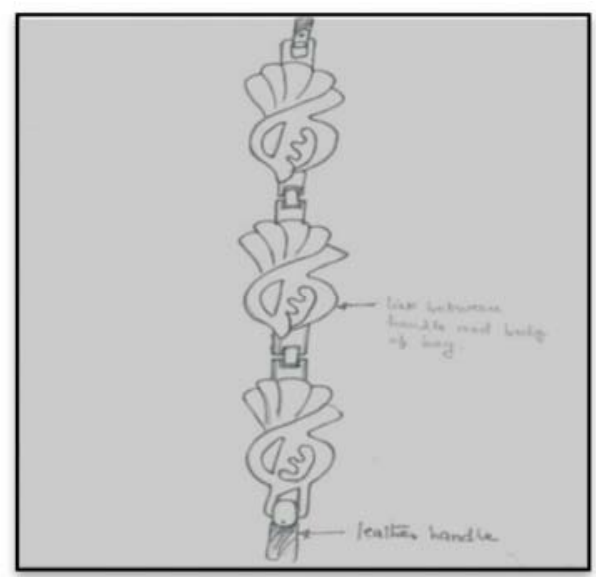

Figure 3. Sketch of bag links.

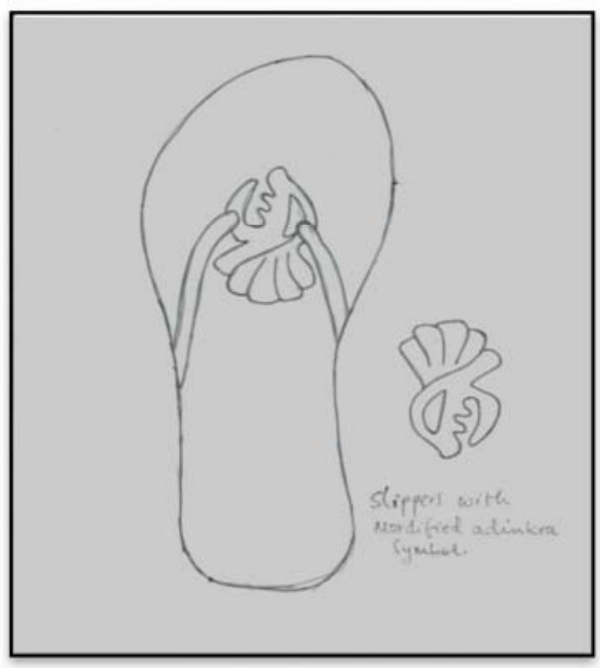

Figure 4. Sketch of slipper with fastener.

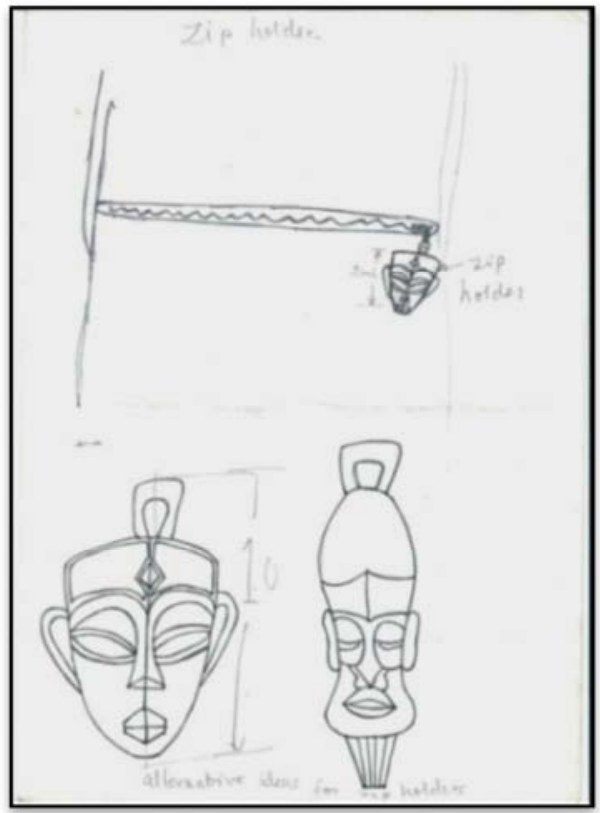

Figure 5. Sketch of purse with fastener.

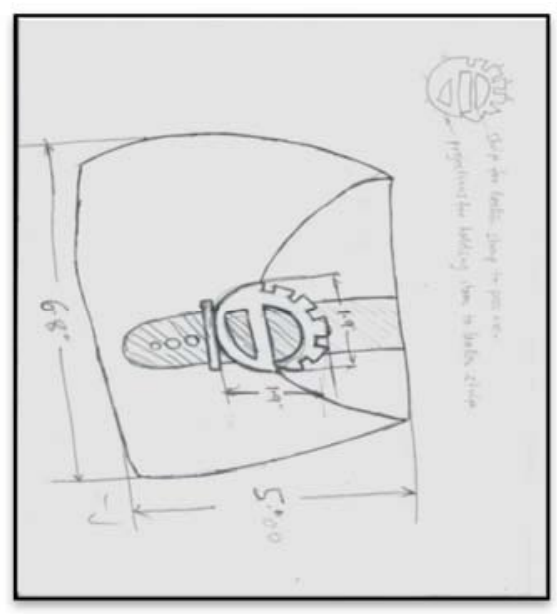

Figure 6. Sketch of zip pull tab.

\subsection{Execution of Designs in Coral Draw}

After developing these sketches, some were selected and were properly outlined and rendered using the CorelDraw software (Figures 7 - 9). This was done so that accurate measurement and orientation of the designs can be obtained and also to allow duplication of the design in the future.

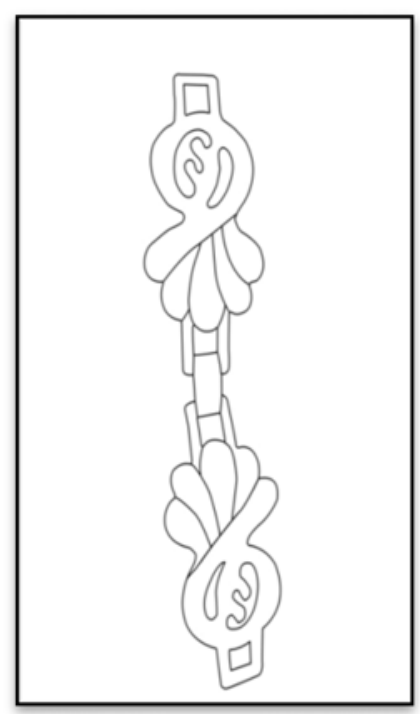

Figure 7. Design for bag links.

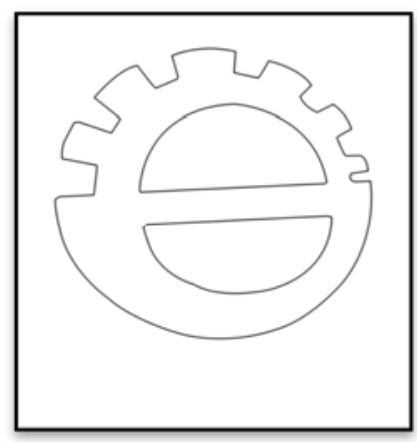

Figure 8. Design for fastener on purse. 


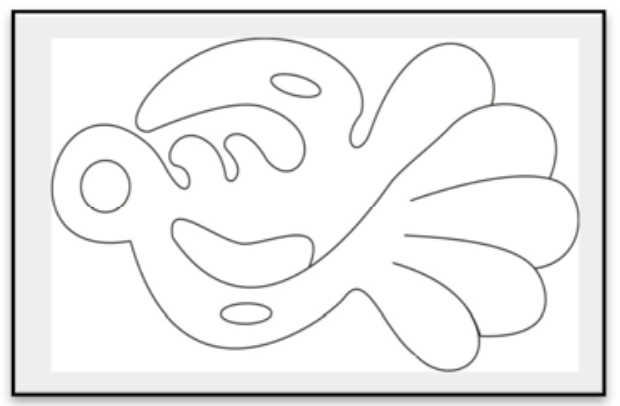

Figure 9. Design for fastener on slipper.

\subsection{Piercing of the Designs}

The surface of the metal to be used was cleaned to ensure proper adhesion of the paper with the design to the surface of the metal. Using white glue, the paper design was pasted onto the brass sheet of one-millimetre $(1 \mathrm{~mm})$ thickness. With the help of the jeweller's saw and blade, the designs were perfectly cut out from the metal sheet as seen in Figure 10. In order to remove the rough edges and sharp corners the works were filed using smooth needle files. Chasing was also done to introduce some lines into the design for further enhancement.

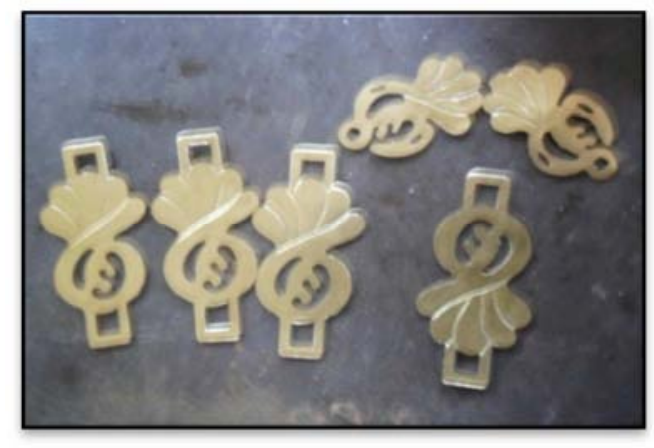

Figure 10. Pierced and chased pattern ready for polishing.

\subsection{Casting}

Another forming technique that was used by the researchers was traditional lost wax casting. This process was adopted to make the pull tab for the zipper on the bag. The following describes the processes adopted.

\subsubsection{Making the Wax Model}

A model of the design was created using bee's wax (Figure 11). In this process, the desired pattern was produced using bee's wax. Since was does not shrink, it could give a very much accurate measurement. The wax model which also served as a prototype of what is desire, was made with the same measurement as required to be seen in the metal. The wax modelling tools also known as "Hyihyi baa" in the Asante Akan language were used in fashioning out the model. Wax welding was employed to join various parts of the model together. The researchers made use of both wax sheets and wax wires in producing the wax model and soap solution was used in preventing the wax from sticking to the surface of the working bench on which modelling was done.

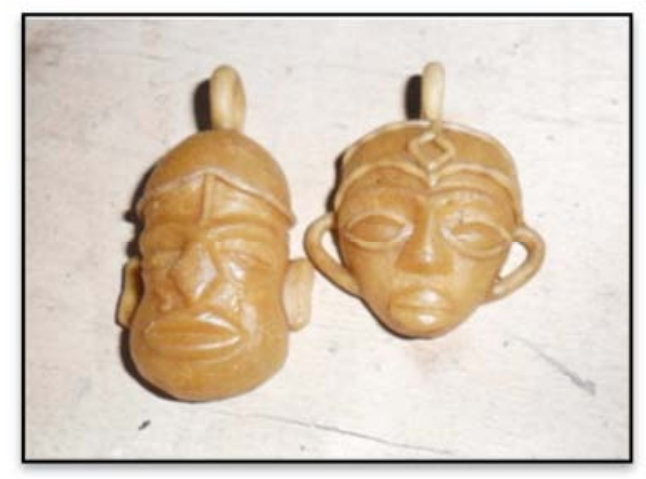

Figure 11. Bee wax model.

\subsubsection{Mould Making for Casting}

First, the wax model was immersed in water and left in the water for approximately a day. This helps the surface of the wax model to accept the refractory slurry for easy coating. The first coat which is made up of 3 parts of fine charcoal powder by volume mixed with 2 parts fine clay and little water to form a paste. The same measurement is used for the second coat but must be of a coarse grain structure of the same material. The final coat which is made up of clay and palm fibre was then applied.

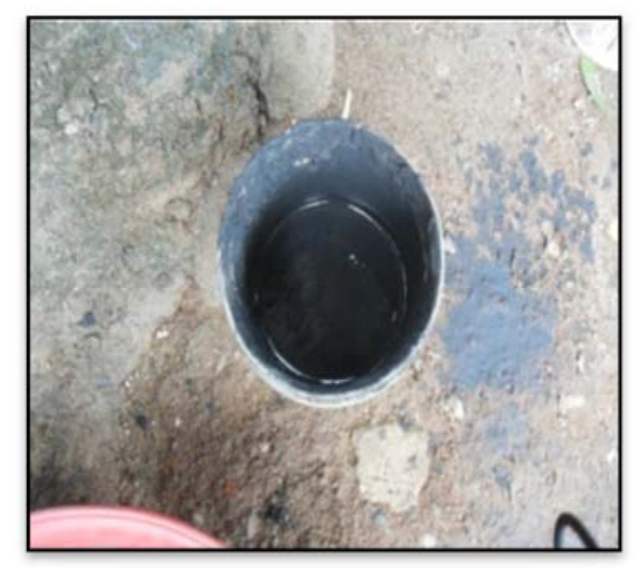

Figure 12. Charcoal mixture.

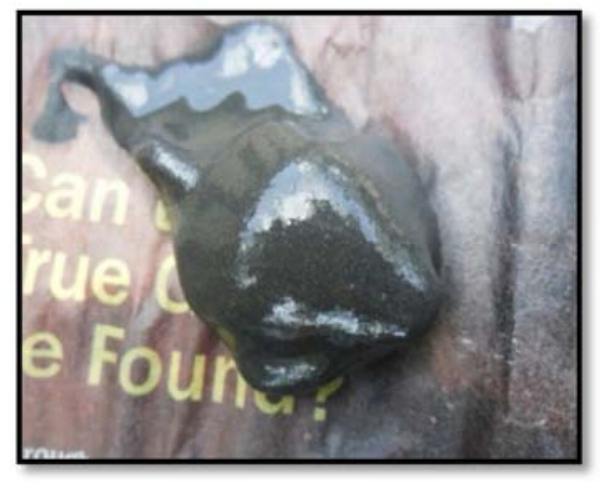

Figure 13. Wax model coated with charcoal-clay mixture. 


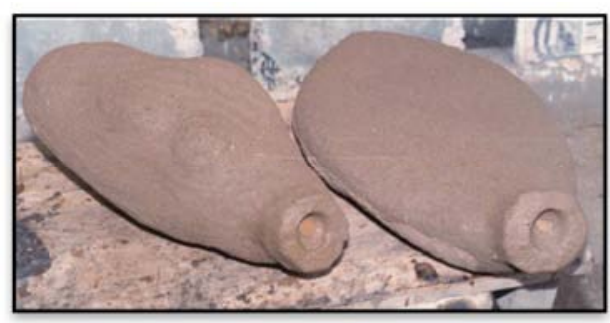

Figure 14. Wax model covered in clay and palm fibre mixture.

\subsubsection{Burn Out and Pouring of Molten Metal}

After the necessary spruces were attached and encased, the wax was burnt out from the mould leaving a cavity in the mould to receive molten metal during pouring. Heating the mould ensured that it was at the right temperature to receive the molten metal (Figure 15). This also helped to keep the molten metal in its molten state so that it did not solidify upon contact with the mould. With the aid of tongs, the molten metal in crucible (Figure 16) was removed from the furnace and poured gently into the hot mould already positioned in place and was allowed to cool.

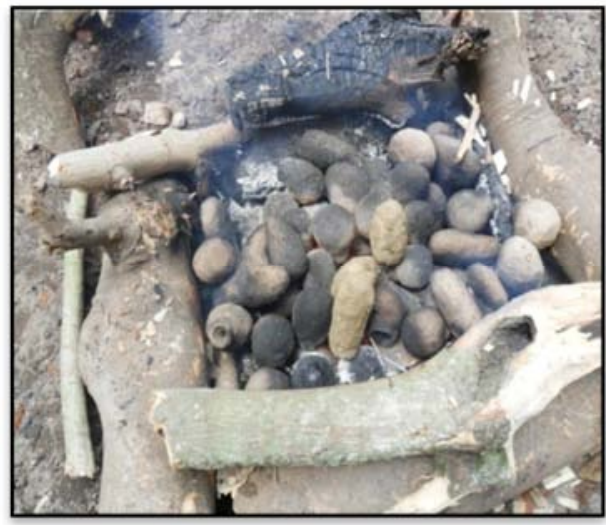

Figure 15. Moulds being heated.

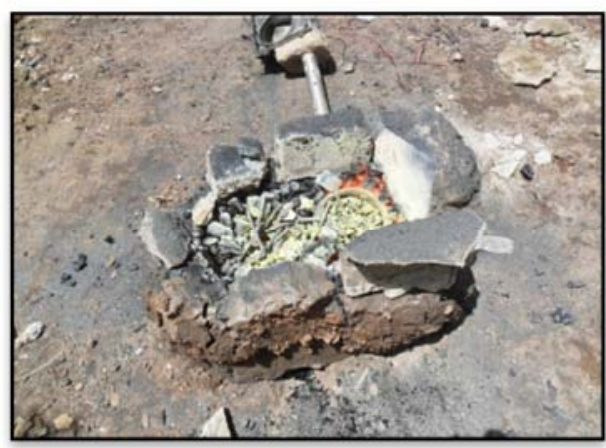

Figure 16. Locally made melting furnace.

\subsubsection{Releasing of Cast Piece}

After the molten metal and mould had properly cooled and solidified, the mould was chiselled into two, freeing the mould from the cast piece. The sprues were sawed off leaving the original cast piece to be finished.

\subsection{Finishing}

The final outcome of the casting process captured the full details of the design but the surface was quite rough. To deliver a good finish to the work, the cast piece was taken through several grades of emerging and polishing. Grades of emery paper from 180 to 600 were used to arrive at the mirror finish desired for the work. In addition to the finishing process, the cast pieces were polished using the polishing wheel together with tripoli and rouge. The cast pieces were finally sprayed with metal lacquer to prevent the surface from tarnishing quickly (Figures 17 - 20).

\subsection{Putting the Parts Together}

To fully demonstrate the ideas intended in this research, the metal fasteners produced were placed on some fashion accessories (bag, purse and slippers) made with Local print fabrics. The metal links were stitched to the right and left sides of the bag and were joined to the handle of the bag. With the help of a brass hook, the pull tab was attached to the zipper so that it hangs on the side pocket of the bag. For the purse, the fastener was stitched to the strip of fabric at the lower side of the purse so that the strip attached to the flap of the purse, can be passed through the fastener to keep it closed (Figure 21-Figure 22). The fasteners on the slipper had oval holes through which the strips of fabric on the slipper were passed through and stitched.

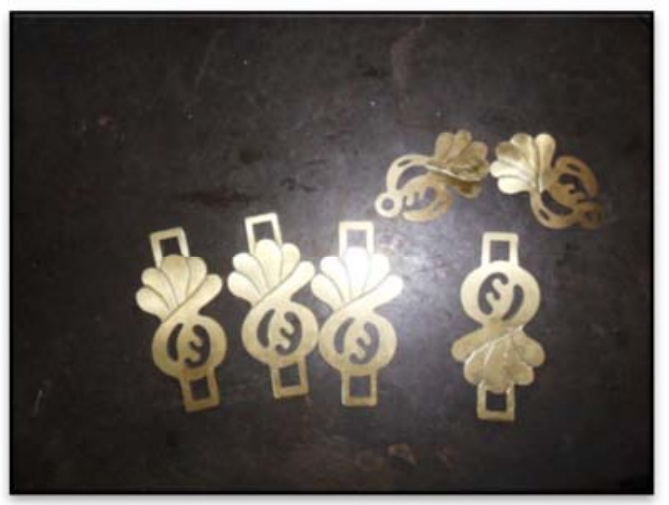

Figure 17. Individual pierced designs.

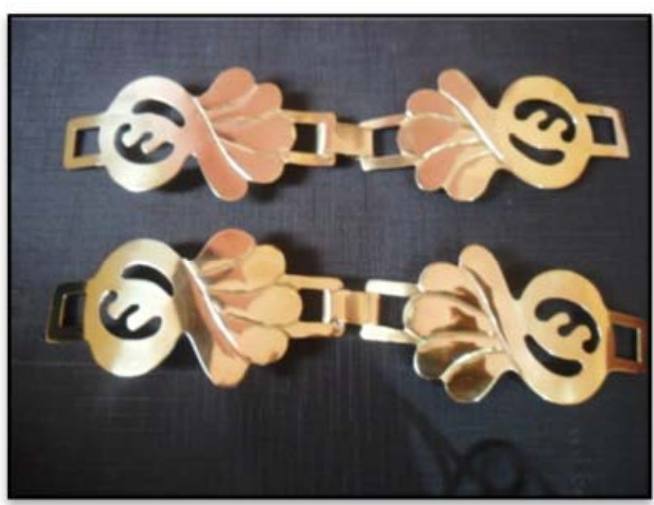

Figure 18. Works linked together and polished. 


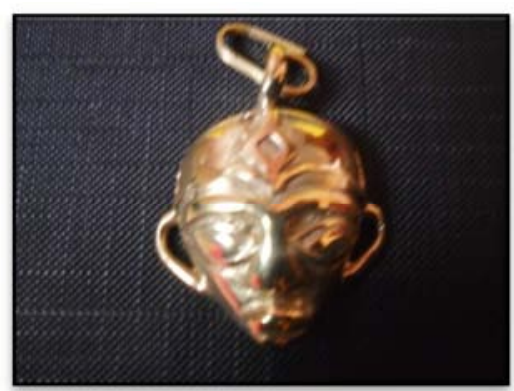

Figure 19. Finished cast piece of pull tab.

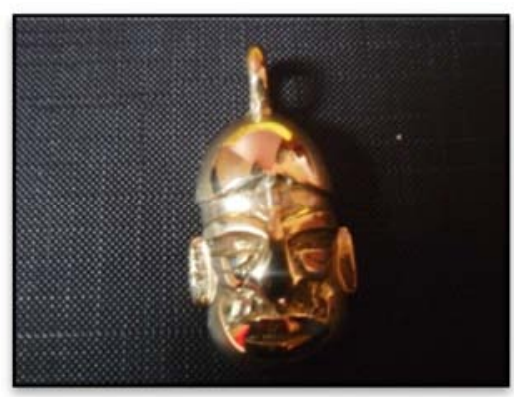

Figure 20. Alternative design for pull tab.

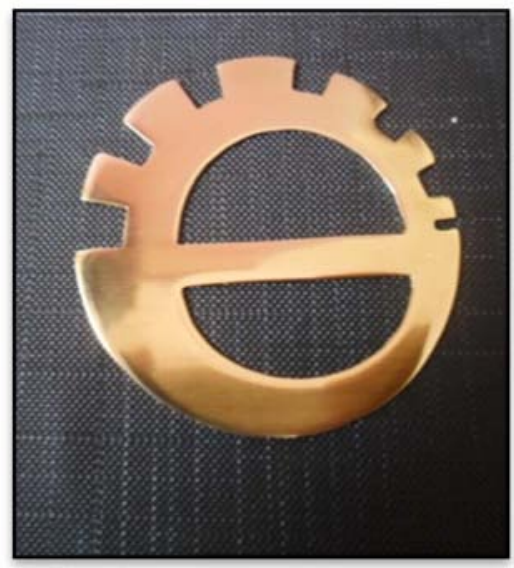

Figure 21. Polished metal fastener for purse.

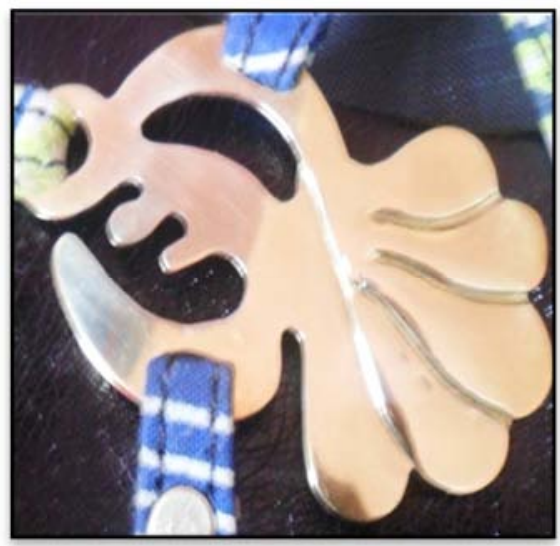

Figure 22. Finished fastener for slipper.

\section{Results and Discussion}

From the field research conducted, metal fasteners are key elements essential to every fashion accessory designer. The demand for these products on the market is quite appreciable and a venture into this area of metalsmithing will lead to job expansion and great revenue. Unfortunately, the problem of metal smiths not venturing into this business can be attributed to the existence of imported metal fasteners which are cheaper as compared to what they can produce. The issue of mass production also stands. Local metalsmiths lack the machinery and technical know-how needed to produce metal fasteners on large scale. This is largely attributed to their limited knowledge on the traditional method of lost wax casting which is just one of the methods that can be used; acquired by apprenticeship. The concept of product design is a bit of an illusion to them. Because of this outstanding difficulty, fashion accessories designers who are the chief consumers of these products further tend to buy these imported fasteners.

The design process produced unique designs developed from two Adinkra symbols (Gye Nyame and Sankofa) and two Ashanti masks. In all, a purse, a bag and a pair of slippers were produced using African print to demonstrate the intended idea.

\subsection{Pair of Slippers}

A pair of slippers was also made using the same African print fabric. Instead of an ordinary ring to hold the nose and the straps of the slippers together, a unique design developed from the Gye Nyame symbol was used. Gye Nyame according to Adom, Opoku, Newton, and Yeboah educates us of God's protection for those who protect and care for the environment [14]. This is one of the most popular of the Adinkra symbols that most Ghanaians can easily relate to and made a good choice for the design and as much as this slipper is comfortable to wear, it also arouses the sense of dignity and culture in the wearer (Figure 23).

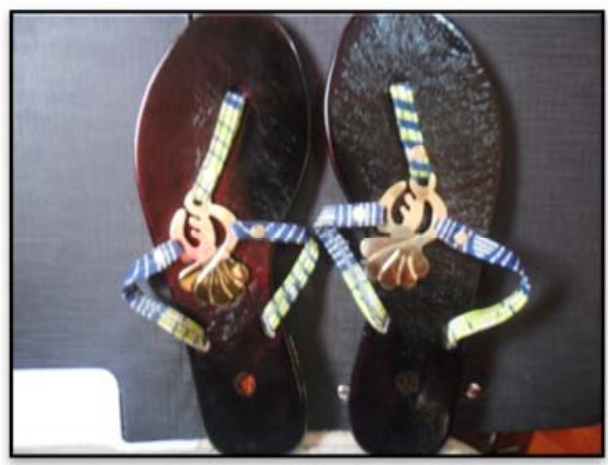

Figure 23. Metal fastener on slipper.

\subsection{The Bag}

The bag has a special pull tab on the zipper designed from an Ashanti mask. The design used for the fastener on the 
slipper was the same used for the links on the bag. This is to help promote the idea of customization in which the user can have a bag and a slipper too much (Figure 24).

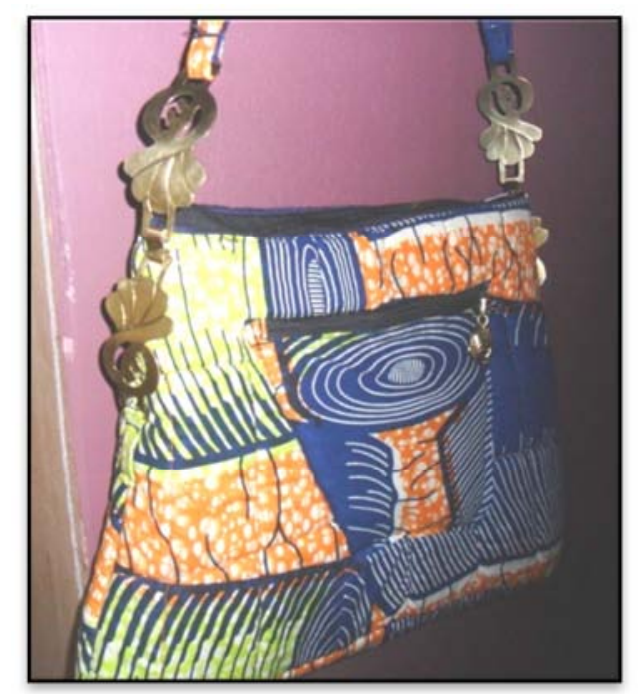

Figure 24. Bag with pull tab and metal links.

\subsection{The Purse}

The purse was also made with African print fabric. The fastener on the purse is made of brass; a very durable material and was designed using the Sankofa symbol. Alabi explains that the Sankofa symbol is one that teaches us about the past and the present. The word is an Asante Akan word that simply means go back and fetch which preaches that the in order to understand the present, you must know the past. [15] Even though this fastener is decorative and symbolic; it also functions well by keeping the purse tightly closed (Figure 25).

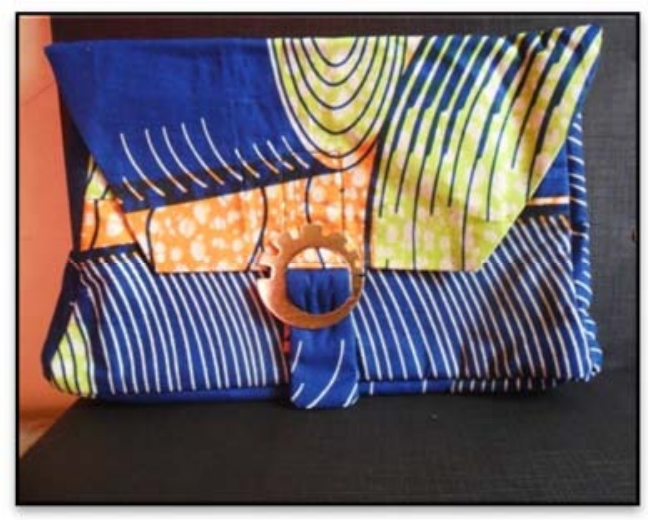

Figure 25. Metal fastener on purse.

\section{Conclusion}

This paper explored the possibility of producing metal fasteners for Ghanaian fashion accessories industry using the Practice-based research methods. From the field research, it can be concluded that local fashion accessories designers make use of imported metal fasteners because they are readily available to them on the open market. This limits their creative abilities to produce local fasteners that equally serve the same purpose. These local metalsmiths have drifted away from this lucrative venture because of the influx of imported metal fasteners on the open market and lack of knowledge of how to produce these items for mass consumption. It can also be stated that, the art of metalsmithing is a creative enterprise which can be fully expressed if those who practice it would move a bit away from their normal practice and explore this venture with their creativity and skill. A typical example is the production of metal fasteners that reflect our culture and values as Ghanaians. This can be achieved by applying the various design processes rather than repeating what has been adopted under apprenticeship. Finally, fabrication processes employed for the study were ones which are practise by the local artisans and are familiar with. But these processes tend to be time consuming and would be a challenge if the products are to be mass producted.

\section{Recommendation}

The researchers would like to recommend that the Ghanaian fashion industry take advantage of the technical knowledge and skill of the Ghanaian metal art industry by partnering with them to produce the fasteners they need instead of importing them. This will help create the needed market that the artisans need. This will also require the state to come out with policies that will reduce the importation of such fasteners and accessories so to help create a niche market for jewellers and metalsmiths to start mass production of such items for the fashion industry.

Techniques for the production can also be improved by adopting new production practices such as laser cutting and investment casting methods which will go a long way to reduce time and labour involved in the process.

\section{References}

[1] Fashion (2012, March 29), retrieved from http://www.wwd.com/fashion-news

[2] Turini, S. (2018, July 2). Man Repeller; I Asked a Bunch of Industry People: What's the Point of Fashion? [Discussion list message] Retrieved from https://www.manrepeller.com/2018/02/meaning-offashion.html

[3] Steele, V. (2020). Beauty and fashion, Retrieved from https://fashion-history.lovetoknow.com/alphabetical-indexfashion-clothing-history/definitionn-fashion

[4] Watkins, Susan. Clothing: The Portable Environment. Ames: Iowa State University Press, 1995.

[5] Friedel: (1996). Zipper: An Exploration in Novelty. Norton and Company: New York.

[6] Epstein, Diana, and Safro, M. (1991). Buttons. New York: Harry N. Abrams. 
[7] Decorative Zips and Fashion Trends. (2020, January 11). What actually is clothing fastener? Retrieved from https://www.sbs-zipper.com/blog/what-actually-is-a-clothingfastener/

[8] National Friday Wear Programme launched (2004, November 12) Retrieved from https://www.ghanaweb.com/GhanaHomePage/NewsArchive/ National-Friday-Wear-Programme-launched-69720

[9] Willis, B. (1998, January 1). The Adinkra dictionary: A visual primer on the language of Adinkra. Pyramid Complex.

[10] Boddy-Evans, A. (2020, February 12). The Origin and Meaning of Adinkra Symbols. Retrieved from https://thoughtco.com/origin-and-meaning-of-adinkrasymbols-4058700.

[11] Bulgin. M, (2001). Adinkra Symbols: To say good bye to a dead relative or friend.
[12] Bello, E. (2017, June 22). Adinkra Symbols of West AfricaHistory and Meaning. Retrieved from https://zoede.com/adinkra-symbols-west-africa-historymeaning/

[13] Skains, L. (2020, August 12). Creative Practice as Research: Discourse on Methodology. [Web log post]. Retrieved from https://scalar.usc.edu/works/creative-practice-research/whatis-pbr

[14] Adom, D., Opoku, M., Newton, J. and Yeboah, A. (2018, May 3) Adinkra Cultural Symbols for Environmental Sustainability Education in Ghana, Journal of World Environment, Volume 8, 10.5923/j.env.20180802.02

[15] Alabi, J. (2020, May 12), Adinkra symbols: a comprehensive list with meanings in Ghana, Retrieved from https://yen.com.gh/109014-adinkra-symbols-acomprehensive-list-meanings-ghana.html 